\title{
Desafios do diagnóstico da leishmaniose visceral canina: relato de caso
}

\section{Challenges in the diagnostic of canine visceral leishmaniasis: case report}

\section{Resumo}

A leishmaniose visceral é uma zoonose causada por protozoários que parasitam o sistema monocítico fagocitário, e tem o cão como principal reservatório urbano. O diagnóstico é difícil de ser realizado devido à diversidade de sinais clínicos e à ocorrência de casos assintomáticos. Deste modo, a confirmação desta doença é obtida com o emprego de métodos laboratoriais. Este estudo relata um caso de leishmaniose visceral canina, no qual o paciente apresentava ampla variação de sinais clínicos, sendo necessário o conhecimento do médico-veterinário sobre a doença para o estabelecimento do diagnóstico correto.

\section{Abstract}

Visceral leishmaniasis is a zoonotic disease caused by the protozoa of the mononuclear phagocyte system, having dogs as its main urban host. Clinical diagnosis is difficult to perform because of the diversity of clinical signs and the occurrence of asymptomatic cases. Thus, the disease is confirmed by employing laboratory methods. This study reports a case of canine visceral leishmaniasis in which the patient presented several clinical signs, and the veterinarian's knowledge about the disease was necessary to establish the correct diagnosis. 
Ana Claudia Scatolim de Almeida

Beatrice Ingrid Macente ${ }^{2}$

Bruna Aparecida de Souza Marques ${ }^{3}$

Bruna Cássia de Souza Poletto 3

Maísa de Cássia Caris Fantin ${ }^{3}$

Rafaela Falkini Dias ${ }^{3}$

Renata Ribeiro Latorre ${ }^{4}$
Endereço para correspondência:

Avenida João Garcia, 728

Centro, General Salgado/SP, Brasil

CEP: 15300-000

\anaclaudia_scatolim@hotmail.com

\section{Palavras-chave}

Zoonose. Cão. Diagnóstico diferencial.

\section{Keywords}

Zoonosis. Dog. Differential diagnosis.

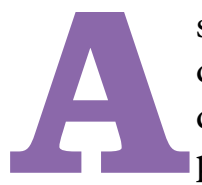

s leishmanioses são doenças de notificação compulsória que requerem ampla investigação epidemiológica para definir as estratégias de controle (BRASIL, 2003). Elas podem se apresentar sob diferentes formas clínicas e são genericamente divididas em dois grandes grupos: a leishmaniose tegumentar (LT) e a leishmaniose visceral (LV). A LV é considerada a forma mais grave, uma zoonose que tem no cão seu principal reservatório no ciclo peri-doméstico (FEITOSA et al., 2000).

No Brasil, a LV é causada pelo agente Leishmania infantum chagasi, protozoário que parasita o sistema monocítico fagocitário do hospedeiro. Os flebotomíneos da espécie Lutzomyia longipalpis, também conhecida por mosquito-palha, birigui ou tatuquira, se constituem no principal vetor relacionado à dispersão do agente (CAMARGO et al., 2007).

A prevalência da leishmaniose visceral canina (LVC) varia de 2,5 a $46,6 \%$ em áreas endêmicas. No Brasil, a doença antes restrita às áreas rurais do Nordeste, avançou para outras regiões indenes alcançando, inclusive, grandes centros urbanos (BRASIL, 2006).

No cão, os sinais clínicos mais frequentes da LV incluem: dificuldade locomotora, emagrecimento progressivo, onicogrifose, apatia, anorexia, diarreia, epistaxe, melena, sinais de insuficiência renal, como-poliúria, polidpsia e vômito, sendo que $90 \%$ dos cães também apresentam algum envolvimento cutâneo, como nódulos intradérmicos e úlceras

Aprimoranda em Patologia Clínica Veterinária da Universidade Brasil, Fernandópolis/SP.

Docente de Medicina Veterinária da Universidade Brasil, Fernandópolis/SP.

Aprimoranda em Clínica e Cirúrgica de Pequenos Animais da Universidade Brasil, Fernandópolis/SP.

Patologista clínica do Laboratório de Patologia Clínica Veterinária da Universidade Brasil, Fernandópolis/SP. 
(FEITOSA et al., 2000). Dentre os achados do exame físico merecem destaque a linfoadenomegalia, onicogrifose, caquexia, hipertermia, hepatoesplenomegalia, uveíte e conjuntivite (SALZO, 2008). A variabilidade das manifestações clínicas da doença, bem como a ocorrência de casos assintomáticos, dificulta o diagnóstico, o qual é confirmado por métodos laboratoriais (SOLANO-GALLEGO et al., 2009).

O diagnóstico laboratorial da LVC era inicialmente realizado pelas técnicas sorológicas de imunofluorescência indireta (RIFI) e por ensaio imunoenzimático (ELISA), de acordo com determinação ministerial (BRASIL, 2006). A partir de 2012, o Ministério da Saúde passou a recomendar o uso do teste rápido (DPP), seguido do teste ELISA (EIE-ELISA), ambos do Biomanguinhos', para confirmação do diagnóstico. Entretanto, a sorologia não apresenta $100 \%$ de sensibilidade e especificidade, podendo ocorrer resultados falso-negativos e falso-positivos decorrente do estágio de evolução da doença ou mesmo reações cruzadas com outros agentes (ALVES; BEVILACQUA, 2004).

Os exames de citologia têm sido utilizados como testes confirmatórios do diagnóstico sorológico. A observação de formas amastigotas de Leishmania spp. em esfregaços de aspirados citológicos de medula óssea ou linfonodos permitem, diante da identificação do parasito, confirmar e garantir a segurança no diagnóstico e na definição da conduta clínica (ALVAR et al., 2004).

A técnica de reação em cadeia pela polimerase (PCR) também tem sido utilizada, por permitir identificar e amplificar, seletivamente, fragmento de DNA do parasita, a partir de diferentes tipos de amostras biológicas, como sangue, aspirados de medula ou linfonodos, biópsias de pele, urina e suabe conjuntival (ALVAR et al., 2004).

Porém, a realização de técnicas moleculares requer laboratórios bem equipados e habilidade técnica (BRASIL, 2003).

Este trabalho relata um caso de LVC, abordando os aspectos clínicos apresentados e os recursos diagnósticos empregados, discutindo a interpretação correta de cada um, objetivando, assim, auxiliar médicos-veterinários a entenderem melhor esta doença e a considerá-la em seus diagnósticos diferenciais.

\section{Descrição do caso}

Um cão da raça teckel, macho, com seis anos de idade e pesando $11 \mathrm{~kg}$, foi atendido no Hospital Veterinário Universidade Brasil, em Fernandópolis/SP, apresentando quadro clínico de claudicação em membro torácico direito, anorexia, vômito e diarreia há uma semana, com histórico de já ter sido acometido por erliquiose há cinco meses. Ao exame físico o cão se mostrou apático; o membro torácico direito em região de carpo estava edemaciado, com dor à palpação; linfonodos poplíteos e submandibulares aumentados de tamanho (reativos).
Para auxiliar o diagnóstico, foram solicitados exames laboratoriais e de imagem, que incluíam hemograma completo, avaliação bioquímica da função renal (creatinina) e hepática (alanina aminotransferase e fosfatase alcalina), urinálise e ultrassonografia abdominal, respectivamente.

O eritrograma apresentou anemia normocítica e normocrômica, não regenerativa, com a contagem de eritrócitos abaixo dos valores de referência (eritrócitos: 4,68 x 106/ $/ \mathrm{mm}^{3}$; referência: $5-8 \times 10^{6} / \mathrm{mm}^{3}$ ). O leucograma estava dentro do padrão de normalidade $\left(14 \times 10^{3} / \mathrm{mm}^{3}\right)$, bem como a contagem de plaquetas (plaquetas: $200 \times 10^{3} / \mathrm{mm}^{3}$; referência: $\left.200-400 \times 10^{3} / \mathrm{mm}^{3}\right)$. Observou-se ainda hiperproteinemia (proteína plasmática total: $10,4 \mathrm{~g} / \mathrm{d}$; referência: $6-8 \mathrm{~g} / \mathrm{d}$ ). As demais avaliações bioquímicas estavam dentro dos valores de referência.

As alterações encontradas na urinálise foram relacionadas às análises químicas, nas quais o $\mathrm{pH}$ urinário apresentou-se ácido, com proteinúria $(++)$ e glicosúria $(+)$. $\mathrm{Na}$ análise microscópica do sedimento urinário foram observados vários tipos de cilindros (granulosos, hialinos e céreos). Por refratometria foi avaliada a densidade urinária (1.012), estando abaixo dos valores esperados à um cão hígido (referência: 1.020-1.045), indicando isostenúria (1.007-1.013).

$\mathrm{Na}$ ultrassonografia foi constatado espleno e hepatomegalia, fígado com ecogenicidade diminuída e arquitetura vascular com calibres dilatados, sugerindo sinais de congestão. Os rins estavam com ecogenicidade elevada e discreta perda da definição/relação córtico-medulares, sinais estes sugestivos de glomerulonefrite ou insuficiência renal. A vesícula urinária se apresentou com paredes discretamente espessadas e sedimentação ecogênica moderada, mas sem evidências de litíase.

Diante dos achados, a suspeita clínica recaiu sobre diabetes melito, doença renal ou LVC. Logo, para a obtenção de um diagnóstico preciso, indicou-se a realização de outros exames complementares: relação proteína/creatinina urinária (UPC), dosagens de glicose sérica, sorologia específica para leishmaniose e citologia aspirativa por agulha fina (CAAF) dos linfonodos reativos.

A UPC apresentou-se em valor superior ao de referência $(0,63 \mathrm{mg} / \mathrm{dl}>5 \mathrm{mg} / \mathrm{dl})$ demonstrando quadro de doença renal glomerular. A glicose sérica $(77 \mathrm{mg} / \mathrm{dl})$ estava dentro dos valores de referência (70-110 mg/dl), sugerindo falha na absorção de glicose pelos túbulos renais.

Foi realizada a sorologia para LVC por meio do método de ensaio imunoenzimático ELISA (ELISA $/ \mathrm{S}^{\circ}$ - Biogene) e a técnica de imunofluorescência indireta (RIFI), que expressam os níveis de anticorpos específicos circulantes. Ambos os resultados foram reagentes à Leishmania spp. (RIFI-titulação: 1:640; ponto de corte: 1:40/ELISA; densidade óptica: 0,402 ; ponto de corte: 0,239$)$.

A CAAF dos linfonodos reativos obteve resultado positivo, com presença de formas amastigotas de Leishmania spp. livres e no interior de monócitos (Figura 1). 

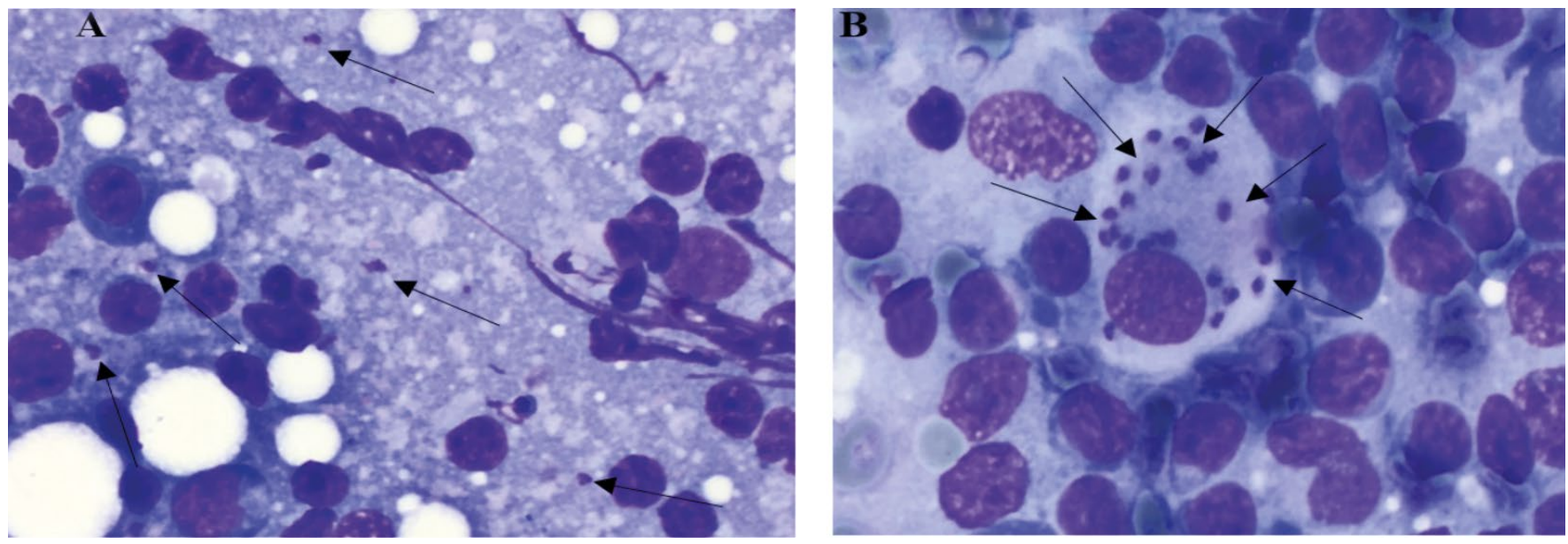

Figura 1 - Fotomicrografia dos esfregaços da CAAF de linfonodos reativos do cão. Fonte: Laboratório de Patologia Clínica, Universidade Brasil, Fernandópolis/SP.

Nota: Podemos observar formas amastigotas de leishmanias spp., ovais e pequenas (2 a 4 mícrons) - (setas), livres pelo esfregaço (A) e dentro do monócito (B). As formas amastigotas possuem um núcleo oval e roxo-claro, com cinetoplasto pequeno e roxo-escuro, em forma de bastão (Panótico Rápido, aumento de 100x, imersão)

Diante da confirmação do diagnóstico, a conduta do médico-veterinário responsável foi realizar a notificação, como previsto pela lei. O tutor do paciente foi orientado da melhor forma, esclarecendo as possibilidades de tratamento controlado, o prognóstico muito reservado de cura, podendo ocorrer recidivas, além dos riscos por ser uma zoonose. Devido à condição geral do animal o tutor optou pela eutanásia.

A eutanásia foi realizada por meio de uma anestesia geral prévia com propofol intravenoso, seguida de cloreto de potássio, método que cientificamente produz uma morte humanitária. Na necropsia do animal, o trato gastrointestinal encontrava-se com conteúdo mucoide, sugestivo de um quadro de gastroenterite: o fígado e o baço, com dimensões severamente aumentadas. Ao corte transversal dos rins pôde-se observar perda da definição/relação córtico-medulares. Devido às condições financeiras do tutor, não foi possível prosseguir com as análises histopatológicas das amostras coletadas.

\section{Discussão}

A anemia observada pode ser classificada como leve a moderada (eritrócitos: 4,68 × 10\% $/ \mathrm{mm} 3$ e hematócrito: $32 \%$ ), assim como outros autores, que já observaram valores médios na contagem de eritrócitos $\left(4,96 \times 10^{6} / \mathrm{mm}^{3}\right.$ e hematócrito: $\left.33,33 \%\right)$ para casos de leishmaniose visceral canina (MEDEIROS et al., 2008). O quadro anêmico com caráter não-regenerativo gera um prognóstico desfavorável, pois a produção eritrocitária na medula óssea encontra-se comprometida.

Um achado frequente em cães com leishmaniose visceral é a hiperproteinemia, decorrente da produção elevada de anticorpos ( $\gamma$ globulina), o que eleva a proteína plasmática total a valores que podem exceder $10 \mathrm{~g} / \mathrm{dL}$ (IKEDA-GARCIA et al., 2003).
Ao que se refere à leucometria, por se tratar de um processo crônico, a resposta leucocitária se modifica de acordo com a evolução da doença. No tocante à contagem de plaquetas, a trombocitopenia pode ser explicada por uma alteração da parede vascular devido à vasculite, distúrbios de trombocitopoiese, aumento na destruição plaquetária ou como consequência do comprometimento do funcionamento renal e/ou hepático (SCHULTZE, 2000).

Embora os parâmetros de função renal e hepática estivessem dentro do padrão de normalidade, oscilações dos níveis de constituintes séricos em cães com LVC têm sido registradas à medida que progride o quadro clínico e devem ser consideradas quando se avaliam infecções crônicas (TRYPHONAS et al., 1977).

Com relação às alterações urinárias, o pH ácido já foi relatado em estudo de Dias (2008), o qual demonstrou que animais acometidos pela LVC costumam apresentar um $\mathrm{pH}$ mais ácido. A cilindrúria e proteinúria podem indicar principalmente afecções glomerulares, enquanto a glicosúria e isostenúria indicam que a lesão tem envolvimento tubular (THRALL et al., 2017). A glomerulonefrite na LVC se origina da deposição de imunocomplexos nos rins, podendo levar a insuficiência renal (FEITOSA et al., 2000).

Os resultados do exame ultrassonográfico e de necropsia foram compatíveis às alterações sistêmicas mais comuns em casos de LVC. A gastroenterite pode ser consequência da insuficiência renal ou resultado de um dano parasitário direto. As leishmanias se multiplicam em macrófagos do fígado e baço, resultando em hepatoesplenomegalia e hepatite (FEITOSA et al., 2000).

A RIFI revelou elevado título de anticorpos no soro (1:640). Em cães, o resultado é considerado reagente 
quando igual ou superior ao ponto de corte (1:40). No teste sorológico de ELISA o resultado reagente é aquele que apresenta o valor da densidade óptica igual ou superior ao ponto de corte (BRASIL, 2006). Neste caso, o valor da densidade óptica de 0,402 foi superior ao ponto de corte: 0,239, ou seja, o cão apresentava anticorpos anti-Leishmania.

$\mathrm{Na}$ CAAF foi observada a presença de formas amastigotas de Leishmania spp. associadas a padrões de celularidade descritos na literatura, com presença de neutrófilos, macrófagos, linfócitos e plasmócitos, encontrando-se várias formas amastigotas dentro de macrófagos e/ou livres na lâmina (COWELL et al., 2009). O exame citológico caracteriza-se pela facilidade e rapidez de execução, baixa agressão tecidual e elevada especificidade (BRASIL, 2003). No entanto, em muitos casos, especialmente em cães assintomáticos, nos quais poucas formas amastigotas estão presentes, podem ocorrer resultados falso-negativos.

Apesar da PCR ser um método que vem demonstrando grande sensibilidade para a detecção de DNA de Leishmania spp. em uma variedade de materiais biológicos, o teste ainda não é indicado pelos programas de vigilância e controle da LV instituídos pelo Ministério da Saúde. Atualmente, a PCR é utilizada em pesquisas e individualmente, para elucidação de casos inconclusivos da doença, principalmente em novos focos (GOMES et al., 2007). Para utilização em larga escala, ajustes são necessários para padronização da técnica e diminuição do custo operacional (GONTIJO; MELO, 2004).

Neste relato de caso, as alterações clínicas e laboratoriais foram sugestivas de LVC e a associação dos sinais clínicos com os achados laboratoriais (anemia, hiperproteinemia, glicosúria, proteinúria e isostenúria), bem como as alterações em baço, fígado e rins, auxiliaram no diagnóstico. A LVC tem sempre sido considerada entre os diagnósticos diferenciais na rotina dos médicos-veterinários na cidade de Fernandópolis, noroeste do estado de São Paulo, por fazer parte de uma região considerada endêmica para a leishmaniose (HIRAMOTO et al., 2019). Vale ressaltar que o diagnóstico da LVC só deve ser estabelecido após combinação da sintomatologia clínica apresentada pelo cão, da situação epidemiológica da região e dos resultados de exames complementares (ALVAR et al., 2004; SOLANO-GALLEGO et al., 2009).

\section{Conclusão}

Cabe ao médico-veterinário conhecer a multiplicidade de sinais clínicos e a correta interpretação dos métodos de diagnóstico, suas limitações e indicações, aplicando-os corretamente para a obtenção de um diagnóstico preciso e seguro. Por se tratar de um caso atendido em uma região endêmica, a LVC é sempre uma doença a ser incluída nos diagnósticos diferenciais, mas que precisa ser considerada sempre pelos clínicos de todo o país. ()

\section{Referências}

ALVAR, J. et al. Canine leishmaniasis. Advances in Parasitology, London, v. 57, n. 4, p. 1-88, 2004.

ALVES, W. A.; BEVILACQUA, P. D. Reflexões sobre a qualidade do diagnóstico da leishmaniose visceral canina em inquéritos epidemiológicos: o caso da epidemia de Belo Horizonte, Minas Gerais. Caderno de Saúde Pública, Rio de Janeiro, v. 10, n. 1, p. 259-265, 2004.

BRASIL. Ministério da Saúde. Manual de vigilância e controle da leishmaniose visceral. Brasília, DF, 2003. 120 p.

BRASIL. Ministério da Saúde. Leishmaniose visceral grave: normas e condutas. Brasília, DF, 2006. 62 p.

CAMARGO, J. B. et al. Leishmaniose visceral canina: aspectos de saúde pública e controle. Clínica Veterinária, São Paulo, n. 71, p. 86-92, 2007.

COWELL, R. L. et al. Diagnóstico citológico e hematologia de cães e gatos. 3. ed. São Paulo: MedVet, 2009. 476 p.

DIAS, C. A. Estudo das alterações clínico laboratoriais e histopatológicas renais em cães com leishmaniose visceral naturalmente infectados no Distrito Federal. 2008. Dissertação (Mestrado em Saúde Animal) - Faculdade de Agronomia e Medicina Veterinária, Universidade de Brasília, Brasília, DF, 2008.

FEITOSA, M. M. et al. Aspectos clínicos de cães com leishmaniose visceral no município de Araçatuba, São Paulo (Brasil). Clínica Veterinária, São Paulo, v. 5, n. 28, p. 36-44, 2000.

GOMES, A. H. et al. PCR identification of Leishmania in diagnosis and control of canine leishmaniasis. Veterinary Parasitology, Amsterdam, v. 144, n. 3-4, p. 234-241, 2007.

GONTIJO, C. M. F.; MELO, M. N. Leishmaniose visceral no Brasil. Revista Brasileira de Epidemiologia, São Paulo, v. 7, n. 3, p. 338-349, 2004.

HIRAMOTO, R. M. et al. Classificação epidemiológica dos municípios do estado de São Paulo segundo o Programa de Vigilância e Controle de Leishmaniose Visceral. Boletim Epidemiológico Paulista, São Paulo, v. 16, p. 1-35, 2019.

IKEDA-GARCIA, F. A. et al. Perfil hematológico de cães naturalmente infectados por Leishmania chagasi no município de Araçatuba - São Paulo: estudo retrospectivo de 191 casos. Clínica Veterinária, São Paulo, v. 47, p. 42-47, 2003.

MEDEIROS, C. M. O. et al. Perfil hematológico de cães com leishmaniose visceral no município de Fortaleza-Ceará. Ciência Animal, Fortaleza, v. 18, n. 1, p. 43-50, 2008.

SALZO, P. S. Aspectos dermatológicos da leishmaniose canina. Nosso Clínico, Jacareí, n. 63, p. 30-34, 2008.

SCHULTZE, A. E. Interpretation of canine leukocyte responses. In: FELDMAN, B. V.; ZINKL, J. G.; JAIN, N. C. (ed.). Schalm's 
veterinary hematology. 5. ed. Philadelphia: Lippincott Williams \& Wilkins, 2000. p. 366-381.

SOLANO-GALLEGO, L. et al. Directions for the diagnosis, clinical staging, treatment and prevention of canine leishmaniosis. Veterinary Parasitology, Amsterdam, v. 165, p. 1-18, 2009.
THRALL, M. A. et al. Hematologia e bioquímica clínica veterinária. 2. ed. Rio de Janeiro: Rocca, 2017.

TRYPHONAS, L. et al. Visceral leishmaniasis in dog: clinical, hematological and pathological observations. Canadian Journal of Comparative Medicine, Ottawa, v. 41, p. 1-12, 1977. 